\title{
Clinical Study \\ Haplotype Analysis of Interleukin-8 Gene Polymorphisms in Chronic and Aggressive Periodontitis
}

\author{
Petra Borilova Linhartova, ${ }^{1}$ Jan Vokurka, ${ }^{2}$ Hana Poskerova, ${ }^{2}$ \\ Antonin Fassmann, ${ }^{2}$ and Lydie Izakovicova Holla ${ }^{1,2}$ \\ ${ }^{1}$ Department of Pathophysiology, Faculty of Medicine, Masaryk University, 62500 Brno, Czech Republic \\ ${ }^{2}$ Clinic of Stomatology, Institutions Shared with St. Anne's Faculty Hospital, Faculty of Medicine, Masaryk University, \\ 65691 Brno, Czech Republic
}

Correspondence should be addressed to Lydie Izakovicova Holla; holla@med.muni.cz

Received 27 July 2013; Revised 9 October 2013; Accepted 4 November 2013

Academic Editor: Dennis Daniel Taub

Copyright (c) 2013 Petra Borilova Linhartova et al. This is an open access article distributed under the Creative Commons Attribution License, which permits unrestricted use, distribution, and reproduction in any medium, provided the original work is properly cited.

\begin{abstract}
Objectives. Periodontitis is an inflammatory disease characterized by connective tissue loss and alveolar bone destruction. Interleukin-8 (IL8) is important in the regulation of the immune response. The aim of this study was to analyze four polymorphisms in the IL8 gene in relation to chronic (CP) and aggressive (AgP) periodontitis. Methods. A total of 492 unrelated subjects were included in this case-control association study. Genomic DNA of 278 patients with CP, 58 patients with AgP, and 156 controls were genotyped, using the $5^{\prime}$ nuclease TaqMan assay, for IL8 (rs4073, rs2227307, rs2227306, and rs2227532) gene polymorphisms. Subgingival bacterial colonization was investigated by the DNA-microarray detection kit in a subgroup of subjects $(N=247)$. Results. Allele and genotype frequencies of all investigated IL8 polymorphisms were not significantly different between the subjects with CP and/or AgP and controls $(P>0.05)$. Nevertheless, the A $(-251) / \mathrm{T}(+396) / \mathrm{T}(+781)$ and $\mathrm{T}(-251) / \mathrm{G}(+396) / \mathrm{C}(+781)$ haplotypes were significantly less frequent in patients with $\mathrm{CP}(2.0 \%$ versus $5.1 \%, P<0.02$, OR $=0.34,95 \%$ CI: $0.15-0.78$, resp., $2.0 \%$ versus $4.5 \%, P<0.05, \mathrm{OR}=0.41,95 \% \mathrm{CI}$ : 0.18-0.97) than in controls. Conclusions. Although none of the investigated SNPs in the IL8 gene was individually associated with periodontitis, some haplotypes can be protective against CP in the Czech population.
\end{abstract}

\section{Introduction}

Periodontitis is an inflammatory disease which is initiated and maintained by the gram-negative bacteria of the subgingival biofilm [1]. Specific pathogen associated molecular patterns (PAMPs) and bacterial virulence factors stimulate an inflammatory host response that finally results in destruction of periodontal tissue and tooth loss [2]. Chronic periodontitis (CP) and generalized aggressive forms of periodontitis (AgP) appear to be associated with certain pathogens, including Porphyromonas gingivalis, Campylobacter rectus, Tannerella forsythia, Peptostreptococcus micro, and Treponema species $[3,4]$. Treponema denticola, P. gingivalis, and T. forsythia, characterized as the "red complex," were strongly associated with the clinical progression of chronic periodontitis [15]. In contrast, AgP was more often diagnosed in patients positive for Aggregatibacter actinomycetemcomitans, but there were many individuals with AgP who did not harbor this microorganism [6].

In addition to the microbial challenge, other factors, such as genetics, environment, and host factors, play a role in the pathogenesis of these diseases [7-9]. Various compounds, such as cytokines, representing an important pathway of connective tissue destruction in periodontitis, have been detected in gingival crevicular fluid (GCF). IL-8, a member of the CXC chemokine family, was originally described by Matsushima and Oppenheim [10]. It is the most important chemoattractant and activator of human neutrophils and an important mediator for granulocyte accumulation [11]. IL-8 is involved in the initiation and amplification of acute inflammatory reactions and chronic inflammatory processes. Functions of IL- 8 are mediated through two receptors (CXCR1 and CXCR2); the expression was detected on numerous cell lineages, including neutrophils and epithelial cells [12]. 
Gingival epithelial cells (GEC) are capable of upregulating IL8 expression rapidly in response to A. actinomycetemcomitans challenge, facilitating thus the recruitment of neutrophils as a host defense mechanism [13, 14]. IL8 expression in GEC is induced by $P$. gingivalis [15] and T. forsythia [16]; IL-8 production by gingival fibroblast cultures is also affected by lipopolysaccharides of $P$. gingivalis and $P$. intermedia [17]. The IL-8 levels in gingival crevicular fluid (GCF) are valuable in detecting the inflammation of periodontal tissue [18-20], and periodontal therapy reduces the IL-8 levels in GCF [21].

IL- 8 is encoded by the IL8 gene located on chromosome 4q13-21 (GenBank accession number M28130.1), consisting of four exons, three introns, and the proximal promoter region [22]. Several polymorphisms have been reported in the IL8 gene [23-26] and some of them can regulate the IL-8 production. Some of SNPs in the IL8 gene such as $-845 \mathrm{~T} / \mathrm{C}$ (rs2227532), -738T/C, -251A/T (rs4073, previously referred to as $-353 \mathrm{~A} / \mathrm{T}),+396 \mathrm{~T} / \mathrm{G}$ (rs2227307), and $+781 \mathrm{C} / \mathrm{T}$ (rs2227306) have been studied in patients with AgP or $\mathrm{CP}$ in the Brazilian population [27-32]. In addition, IL8 $-251 \mathrm{~T}$ allele, which was associated with higher production of IL-8, increased the risk of developing acute suppurative form of apical periodontitis (AP), whereas IL8 -251A "lowproducing" allele was associated with chronic nonsuppurative form of AP in the Colombian population [33]. In the Chinese population, IL8 -251A allele has been associated with decreased susceptibility to CP [34]. The cross-sectional study in Iran has also focused on the study of polymorphisms in the IL8 gene but did not specify whether it was for patients with CP or AgP [35]. To date, no study analyzing allele, genotype, or haplotype frequencies of IL8 gene polymorphisms in patients with periodontitis has been performed in Caucasians.

The aim of this study was to associate four SNPs in the IL8 gene (rs4073, rs2227307, rs2227306, and rs2227532) and their haplotypes to $\mathrm{CP}$ and $\mathrm{AgP}$ and subgingival bacterial colonization in the Czech population.

\section{Material and Methods}

The study was performed with the approval of the Committees for Ethics of the Medical Faculty, Masaryk University Brno and St. Anne's Faculty Hospital. Written informed consent was obtained from all participants before inclusion in the study, in line with the Helsinki Declaration.

2.1. Study Population. All patients were recruited from the patient pool of the Periodontology Department, Clinic of Stomatology, St. Anne's Faculty Hospital, Brno, from 2005 to 2011. They had at least 20 remaining teeth and were in good general health. Exclusion criteria included history of cardiovascular disorders (such as coronary artery diseases or hypertension), diabetes mellitus, malignant diseases, immunodeficiency, current pregnancy, or lactation. Controls were selected from subjects referring to the Clinic of Stomatology for reasons other than periodontal disease (such as dental caries, orthodontic consultations, preventive dental checkups, etc.) during the same period as patients and matched for age, gender, and smoking status. Similarly as patients, all controls had at least 20 remaining teeth and were in good general health. Exclusion criteria were the same as those applied for patients with periodontitis.

2.2. Case-Control Association Study. A total of 492 unrelated Caucasian subjects of exclusively Czech ethnicity from the region of South Moravia were included in this case-control association study. Diagnosis of nonperiodontitis/periodontitis was based on the detailed clinical examination, medical and dental history, tooth mobility, and radiographic assessment. Probing depth (PD) and attachment loss (CAL) were collected with a UNC-15 periodontal probe from six sites on every tooth present. The loss of the alveolar bone was determined radiographically. We used the index of Mühlemann to evaluate decreases in alveolar bone levels.

(1) Generalized CP group $(N=278)$ : all patients with chronic periodontitis (CP) fulfilled the diagnostic criteria defined according to CAL levels by the International Workshop for a Classification of Periodontal Diseases and Conditions for Chronic Periodontitis [36]. Inclusion criteria for patients suffering from generalized chronic periodontitis were as follows: $\geq 30 \%$ of the teeth were affected, PD was $\geq 4 \mathrm{~mm}$, and the amount of CAL was consistent with the presence of dental plaque.

(2) Generalized AgP group $(N=58)$ : patients with aggressive periodontitis with age at disease onset $<35$ years, attachment loss of $4 \mathrm{~mm}$ or more in at least $30 \%$ of the teeth (at least three of the affected teeth were not first molars and incisors), and the severity of attachment loss being inconsistent with the amount of dental plaque were included in this study.

(3) Control group (healthy/nonperiodontitis) $(N=156)$ : controls were screened using a WHO probe and the CPITN (Community Periodontal Index of Treatment Needs) was assessed [37]; values of the CPITN index in controls were less than 3.

In order to adjust for the effect of smoking history on periodontal disease, the subjects (patients and controls) were classified into the following groups: subjects who never smoked (referred to as nonsmokers) and subjects who were former smokers for $\geq 5$ pack years or current smokers (referred to as smokers). The pack years were calculated by multiplying the number of years of smoking by the average number of cigarette packs smoked per day.

\subsection{Genetic Analysis}

2.3.1. Isolation of Genomic DNA. DNA for genetic analysis was extracted from the peripheral blood leukocytes using standard phenol/chloroform procedures with proteinase $\mathrm{K}$ according to Sambrook et al. [38]. Isolation and storage of DNA (working samples at concentrations of $50 \mathrm{ng} \mu \mathrm{L}^{-1}$ at $4^{\circ} \mathrm{C}$ ) as well as the genotyping of samples were conducted in the laboratory of the Department of Pathophysiology, Faculty of Medicine, Masaryk University, Brno, Czech Republic. 
2.3.2. SNPs Genotyping TaqMan Assay. Four SNPs (-845C/T rs2227532, -251A/T rs4073, +396G/T rs2227307, and +781C/ $\mathrm{T}$ rs2227306) in the IL8 gene were genotyped using the $5^{\prime}$ nuclease TaqMan assay for allelic discrimination. Individual fluorogenic TaqMan probes, consisting of an oligonucleotide labelled with both a fluorescent reporter dye, FAM, and a quencher dye, VIC, were obtained from Life Technologies (Grand Island, NY, USA). Each reaction mixture was prepared using TaqMan Genotyping Master Mix $(12.5 \mu \mathrm{L})$, TaqMan SNP Genotyping Assay $(1.25 \mu \mathrm{L})$, and $50 \mathrm{ng}$ of genomic DNA in $17.5 \mu \mathrm{L}$ of $\mathrm{dH}_{2} \mathrm{O}$ to make a $25.0 \mu \mathrm{L}$ reaction volume. Genotyping was carried out simultaneously with 88 samples on 96 -well plate (+8 negative controls). Details on SNPs detection are summarized in Table 1. The PCR thermocycling protocol consisted of $10 \mathrm{~min}$ at $95^{\circ} \mathrm{C}$, followed by 40 cycles of $15 \mathrm{~s}$ at $92^{\circ} \mathrm{C}$ and $1 \mathrm{~min}$ at $60^{\circ} \mathrm{C}$. Each genotyping plate contained eight wells without any DNA template (negative controls) and randomly selected duplicate samples (10\% of plate samples). Allele genotyping from fluorescence measurements was then obtained using the ABI PRISM 7000 Sequence Detection System. SDS version 1.2.3 software was used to analyze real-time and endpoint fluorescence data. Genotyping was performed by one investigator (P. B. L.) unaware of the phenotype.

2.3.3. DNA Microarray Analysis of Oral Pathogens. Subgingival bacterial colonization (Aggregatibacter actinomycetemcomitans, Porphyromonas gingivalis, Prevotella intermedia, Tannerella forsythia, Treponema denticola, Peptostreptococcus micros, and Fusobacterium nucleatum) in subgingival pockets was investigated by the DNA microarray based on a periodontal pathogen detection kit (Protean Ltd., Ceske Budejovice, CR) in a subgroup of randomly selected subjects $(N=151$ for $\mathrm{CP}, N=21$ for $\operatorname{AgP}$, and $N=75$ for controls) before subgingival scaling. Microbial samples were collected from the deepest pocket in periodontitis patients (and from the deepest sulcus in healthy subjects) of each quadrant by inserting a sterile paper point into a base of the pocket for 20 seconds. Bacterial plaque samples from each individual were pooled in one tube. This test determined the individual pathogens semiquantitatively as follows: (-) undetected, which corresponds to the number of bacteria less than $10^{3},(+)$ slightly positive corresponding to the number of bacteria $10^{3}$ to $10^{4},(++)$ positive corresponding to the number of bacteria $10^{4}$ to $10^{5}$, and $(+++)$ strongly positive, with the number of bacteria higher than $10^{5}$.

2.4. Statistical Analysis. Comparisons were made between allelic and genotype frequencies in the patients with chronic or aggressive form of periodontitis and control population. The allele frequencies were calculated from the observed numbers of genotypes. The significance of differences in the allele frequencies among groups was determined by Fisher's exact test. $\chi^{2}$ analysis was used to test for deviation of genotype distribution from Hardy-Weinberg equilibrium and comparison of differences in genotype combinations among groups.
To examine the linkage disequilibrium (LD) between all SNPs, pairwise LD coefficients $\left(\mathrm{D}^{\prime}\right)$ and haplotype frequencies were calculated using the SNP Analyzer 2 program (http://snp.istech.info/istech/board/login_form.jsp). Variations in the quantity of subgingival bacteria corresponding to the particular genotypes/alleles were tested by $\chi^{2}$ and Fisher's exact tests. Differences were considered significant at $P<0.05$.

Power analysis was performed with respect to the casecontrol design of the study taking the incidence rate of markers and estimate of the odds ratio (OR) as end-point statistical measures. ORs with corresponding 95\% confidence intervals (CI) were estimated using logistic regression models, adopting age, sex, and smoking as adjusting covariates. All calculations were performed using Statistica ver. 10.0 (StatSoft Inc., Tulsa, OK, USA) and SPSS software (SPSS 20.0.1, IBM Corporation, 2011).

\section{Results}

3.1. Case-Control Study. The mean ages for AgP patients $(37.0 \pm 8.2$; years $\pm \mathrm{SD})$ and healthy subjects $(41.0 \pm 12.3) \mathrm{did}$ not differ between the two groups. However, subjects with CP were significantly older $(47.9 \pm 8.7)$ than the patients with $\mathrm{AgP}$ $(P<0.05)$. Nearly, $27 \%$ of the periodontitis patients $(28.0 \%$ of CP and $26.0 \%$ of AgP) and $28.0 \%$ of healthy subjects were smokers. There were no significant differences between the subjects with periodontitis and controls regarding the mean percentage of smokers and ratio of males/females (77/79 in controls, $136 / 142$ in patients with $\mathrm{CP}$, and $25 / 33$ in patients with AgP).

Sample size of the study was planned in standard power calculation for case-control design of the study with the null and alternative hypotheses expressed on the basis of OR. The design was prospectively optimized assuming the prevalence of examined attribute among controls to be 0.5 . The recruited sample (278 cases, 156 controls) allowed a statistically significant detection of $\mathrm{OR}$ out of the range of 0.55-1.80 (alpha $=0.05$, power $=0.80)$. In case of the AgP group (58 cases, 156 controls), the statistically significantly detectable ORs estimates were out of the range of 0.39-2.59.

3.2. Single Nucleotide Polymorphism Analysis. All studied polymorphisms were in the Hardy-Weinberg equilibrium in the control group. Allele and genotype frequencies of all investigated IL8 polymorphisms were not significantly different between the subjects with $\mathrm{CP}$ and/or AgP and controls $(P>0.05$; Table 2). Considering that in the Czech population, SNP IL8 -845TT genotype occurred in $98.4 \%$ of CP patients and even $100 \%$ of controls and AgP patients, we analyzed this polymorphism only in the subgroup of subjects $(N=193)$.

3.3. Haplotype Analysis. Based on the previous study [29] the haplotype analysis of these selected SNPs was performed in the IL8 gene $(-251 \mathrm{~T} / \mathrm{A}$ rs4073, +396T/G rs2227307, and $+781 \mathrm{C} / \mathrm{T}$ rs2227306). All variants in the IL8 gene were in tight 
TABLE 1: Details of SNPs in IL8 detection.

\begin{tabular}{lcl}
\hline SNPs & TaqMan SNP genotyping assay ID & Context sequence [VIC/FAM] \\
\hline $\begin{array}{l}\text { IL8 } 8 \text {-845T/C } \\
(\mathrm{rs} 2227532)\end{array}$ & C_1842904_10 & $\begin{array}{l}\text { GCTCTTATGCCTCCACTGGAATTAA[C/T] } \\
\text { GTCTTAGTACCACTTGTCTATTCTG }\end{array}$ \\
\hline $\begin{array}{l}\text { IL8 }-251 \mathrm{~A} / \mathrm{T} \\
(\mathrm{rs} 4073)\end{array}$ & C_11748116_10 & $\begin{array}{l}\text { TTATCTAGAAATAAAAAAGCATACA[A/T] } \\
\text { TTGATAATTCACCAAATTGTGGAGC }\end{array}$ \\
\hline $\begin{array}{l}\text { IL8+396T/G } \\
(\mathrm{rs} 222730732)\end{array}$ & C_11748168_10 & TATTCTGCTTTTATAATTTATACCA[G/T] \\
$\begin{array}{l}I L 8+781 \mathrm{C} / \mathrm{T} \\
(\mathrm{rs} 2227306)\end{array}$ & C_11748169_10 & GTAGCATGCATATATTTAACGTAAA \\
\hline
\end{tabular}

TABLE 2: Genotype and allele frequencies of IL8 polymorphisms in control and periodontitis subgroups.

\begin{tabular}{|c|c|c|c|c|c|c|c|c|}
\hline SNP & Genotype & $\begin{array}{c}\text { Controls } \\
N=156(\%)\end{array}$ & $\begin{array}{c}\mathrm{CP} \\
N=278(\%)\end{array}$ & $P$ value ${ }^{*}$ & $\begin{array}{c}\text { OR } \\
(95 \% \mathrm{CI}) \\
\end{array}$ & $\begin{array}{c}\operatorname{AgP} \\
N=58(\%)\end{array}$ & $P$ value* & $\begin{array}{c}\text { OR } \\
(95 \% \mathrm{CI}) \\
\end{array}$ \\
\hline \multirow{6}{*}{$\begin{array}{l}I L 8-251 \mathrm{~T} / \mathrm{A} \\
(\mathrm{rs} 4073)\end{array}$} & $\mathrm{TT}$ & $49(31.4)$ & $95(34.2)$ & - & 1.00 & $18(31.0)$ & - & 1.00 \\
\hline & TA & $78(50.0)$ & $120(43.2)$ & 0.37 & $0.76(0.47-1.23)$ & $27(46.6)$ & 0.76 & $1.08(0.49-2.37)$ \\
\hline & AA & $29(18.6)$ & $63(22.7)$ & 0.78 & $1.22(0.67-2.21)$ & $13(22.4)$ & 0.67 & $1.27(0.47-3.38)$ \\
\hline & Allele & & & \multirow{3}{*}{0.60} & & & \multirow{3}{*}{0.33} & \\
\hline & $\mathrm{T}$ & $176(56.4)$ & $310(55.8)$ & & 1.00 & $62(53.4)$ & & 1.00 \\
\hline & A & $136(43.6)$ & $246(44.2)$ & & $0.93(0.69-1.25)$ & $54(46.6)$ & & $0.89(0.55-1.44)$ \\
\hline \multirow{6}{*}{$\begin{array}{l}I L 8+396 \mathrm{~T} / \mathrm{G} \\
(\mathrm{rs} 2227307)\end{array}$} & $\mathrm{TT}$ & $54(34.6)$ & $100(36.0)$ & - & 1.00 & $20(34.5)$ & - & 1.00 \\
\hline & TG & $74(47.4)$ & 118 (42.4) & 0.58 & $0.86(0.54-1.39)$ & $27(46.6)$ & 0.74 & $1.15(0.54-2.45)$ \\
\hline & GG & $28(17.9)$ & $60(21.6)$ & 0.67 & $1.28(0.71-2.31)$ & $11(19.0)$ & 0.92 & $1.00(0.36-2.82)$ \\
\hline & Allele & & & \multirow{3}{*}{0.83} & & & \multirow{3}{*}{0.89} & \\
\hline & $\mathrm{T}$ & $182(58.3)$ & $318(57.2)$ & & 1.00 & $67(57.8)$ & & 1.00 \\
\hline & G & $130(41.7)$ & $238(42.8)$ & & $0.91(0.68-1.23)$ & $49(42.2)$ & & $0.99(0.61-1.62)$ \\
\hline \multirow{6}{*}{$\begin{array}{l}\text { IL8 +781C/T } \\
(\mathrm{rs} 2227306)\end{array}$} & $\mathrm{CC}$ & $55(35.3)$ & $103(37.1)$ & - & 1.00 & $20(34.5)$ & - & 1.00 \\
\hline & $\mathrm{CT}$ & $76(48.7)$ & $121(43.5)$ & 0.51 & $0.82(0.52-1.31)$ & $27(46.6)$ & 0.84 & $1.10(0.52-2.34)$ \\
\hline & $\mathrm{TT}$ & $25(16.0)$ & $54(19.4)$ & 0.66 & $1.24(0.67-2.31)$ & $11(19.0)$ & 0.66 & $1.07(0.38-3.02)$ \\
\hline & Allele & & & \multirow{3}{*}{0.44} & & & \multirow{3}{*}{0.68} & \\
\hline & $\mathrm{T}$ & $186(59.6)$ & $327(58.8)$ & & 1.00 & $67(57.8)$ & & 1.00 \\
\hline & $\mathrm{C}$ & $126(40.4)$ & $229(41.2)$ & & $1.06(0.78-1.43)$ & $49(42.2)$ & & $1.05(0.64-1.70)$ \\
\hline \multirow{6}{*}{$\begin{array}{l}\text { IL8 -845T/C } \\
\text { (rs2227532) }\end{array}$} & $\mathrm{TT}$ & $52(100.0)$ & $120(98.4)$ & - & 1.00 & $19(100.0)$ & - & 1.00 \\
\hline & $\mathrm{TC}$ & $0(0.0)$ & $2(1.6)$ & 0.49 & \# & $0(0.0)$ & 1.00 & \# \\
\hline & $\mathrm{CC}$ & $0(0.0)$ & $0(0.0)$ & 1.00 & \# & $0(0.0)$ & 1.00 & \# \\
\hline & Allele & & & & & & & \\
\hline & $\mathrm{T}$ & $104(100.0)$ & $242(99.2)$ & \multirow{2}{*}{0.49} & 1.00 & $38(100.0)$ & \multirow{2}{*}{1.00} & 1.00 \\
\hline & $\mathrm{C}$ & $0(0.0)$ & $2(0.8)$ & & \# & $0(0.0)$ & & \# \\
\hline
\end{tabular}

${ }^{*}$ Differences between individual haplotypes (between controls and $\mathrm{CP}$ or controls and $\mathrm{AgP}$ ) were analyzed using the Fisher exact test. OR: odds ratio adjusted for age, sex, and smoking in logistic regression, reference categories designated with an OR of 1.0; CI: confidence interval, ${ }^{*}$ nonapplicable (small numbers); ${ }^{\#}$ OR not calculated because of the presence of zero values.

linkage disequilibrium with each other to various degrees $\left(D^{\prime}=0.793-1.000\right.$ in controls, $D^{\prime}=0.889-0.951$ in patients with $\mathrm{CP}$, and $\mathrm{D}^{\prime}=0.891-1.000$ in patients with $\left.\mathrm{AgP}\right)$. The complex analysis revealed differences in IL8 haplotype frequencies. Specifically, the $\mathrm{A}(-251) / \mathrm{T}(+396) / \mathrm{T}(+781)$ and $\mathrm{T}(-251) / \mathrm{G}(+396) / \mathrm{C}(+781)$ haplotypes were significantly less frequent in patients with $\mathrm{CP}(2.0 \%$ versus $5.1 \%$, resp., $4.5 \%$, $P<0.05$ ) (Table 3 ). The decreased frequency of the TGC haplotype alleles in patients with CP was confirmed by the observation that TGC/TTC haplotype (arranged as genotypes) was less frequent in patients with $\mathrm{CP}(0.4 \%$ versus
2.6\%, $P<0.05$, OR $=0.09,95 \% \mathrm{CI}=0.01-0.96)$. Moreover, an uncommon ATT/ATT haplotype (1.15\% of the studied population) was found more, but nonsignificantly, in nonperiodontitis controls $(2.6 \%$ versus $0.4 \%, P=0.07)$. There was also a nonsignificant trend in the ATC/TTC haplotype association with CP (2.2\% versus $0.0 \%, P=0.08$, Table 4$)$.

3.4. Microbiological Analysis. F. nucleatum occurred less frequently in nonperiodontitis subjects $(N=75)$ positive for T allele of $I L 8+396 \mathrm{G} / \mathrm{T}$ variant $(49.2 \%$ versus $77.8 \%$, $P<0.02 ; \mathrm{OR}=0.28,95 \% \mathrm{CI}=0.09-0.89)$ or TT genotype 
TABLE 3: Distribution of IL8 haplotypes in the studied groups.

\begin{tabular}{|c|c|c|c|c|c|c|c|c|c|}
\hline \multicolumn{3}{|c|}{ Haplotypes (alleles of IL8 SNPs) } & \multirow[b]{2}{*}{$\begin{array}{c}\text { Controls } \\
N=312(\%)\end{array}$} & \multirow[b]{2}{*}{$\begin{array}{c}\mathrm{CP} \\
N=556(\%)\end{array}$} & \multirow[b]{2}{*}{$P^{\mathrm{a}}$} & \multirow[b]{2}{*}{ OR $(95 \% \mathrm{CI})$} & \multirow[b]{2}{*}{$\begin{array}{c}\text { AgP } \\
N=116(\%)\end{array}$} & \multirow[b]{2}{*}{$P^{\mathrm{a}}$} & \multirow[b]{2}{*}{ OR $(95 \% \mathrm{CI})$} \\
\hline $\begin{array}{l}\text { IL8 -251T/A } \\
(\mathrm{rs} 4073)\end{array}$ & $\begin{array}{c}I L 8+396 \mathrm{~T} / \mathrm{G} \\
(\mathrm{rs} 2227307)\end{array}$ & $\begin{array}{l}I L 8+781 \mathrm{C} / \mathrm{T} \\
(\mathrm{rs} 2227306)\end{array}$ & & & & & & & \\
\hline $\mathrm{T}$ & $\mathrm{T}$ & $\mathrm{C}$ & $162(51.9)$ & $293(52.7)$ & NS & $0.99(0.73-1.32)$ & $62(53.4)$ & NS & $1.02(0.63-1.65)$ \\
\hline $\mathrm{A}$ & G & $\mathrm{T}$ & $110(35.3)$ & $212(38.1)$ & NS & $1.17(0.86-1.59)$ & $46(39.7)$ & NS & $1.14(0.70-1.87)$ \\
\hline A & $\mathrm{T}$ & $\mathrm{T}$ & $16(5.1)$ & $11(2.0)$ & 0.018 & $0.34(0.15-0.78)$ & $3(2.6)$ & NS & $0.62(0.18-2.20)$ \\
\hline $\mathrm{T}$ & G & $\mathrm{C}$ & $14(4.5)$ & $11(2.0)$ & 0.048 & $0.41(0.18-0.97)$ & $2(1.7)$ & NS & $0.51(0.11-2.30)$ \\
\hline A & G & $\mathrm{C}$ & $6(1.9)$ & $12(2.2)$ & NS & $1.40(0.47-4.12)$ & $2(1.7)$ & NS & $1.22(0.23-6.35)$ \\
\hline A & $\mathrm{T}$ & $\mathrm{C}$ & $4(1.3)$ & $11(2.0)$ & NS & $1.79(0.54-5.90)$ & $1(0.9)$ & NS & $1.01(0.11-9.29)$ \\
\hline $\mathrm{T}$ & $\mathrm{T}$ & $\mathrm{T}$ & $0(0.0)$ & $3(0.5)$ & NS & $*$ & $0(0.0)$ & NS & $*$ \\
\hline $\mathrm{T}$ & G & $\mathrm{T}$ & $0(0.0)$ & $3(0.5)$ & NS & $*$ & $0(0.0)$ & NS & $*$ \\
\hline & & & & & $P=\mathrm{NS}$ & & & $P=\mathrm{N}$ & \\
\hline
\end{tabular}

OR: odds ratio adjusted for age, sex, and smoking in logistic regression CI: confidence intervals.

${ }^{a}$ Differences between individual haplotypes (between controls and $\mathrm{CP}$ or controls and $\mathrm{AgP}$ ) were analyzed using the Fisher exact test.

* OR not calculated because of the presence of zero values.

Bold: significant result.

TABLE 4: Distribution of IL8 haplotypes (arranged as genotypes) in the studied groups.

\begin{tabular}{|c|c|c|c|c|c|c|c|}
\hline $\begin{array}{l}\begin{array}{l}\text { Haplotypes } \\
\text { (genotypes of IL8 SNPs) } \\
-251 \mathrm{~T} / \mathrm{A},+396 \mathrm{~T} / \mathrm{G}, \\
+781 \mathrm{C} / \mathrm{T} / 251 \mathrm{~T} / \mathrm{A}, \\
+396 \mathrm{~T} / \mathrm{G} \text {, and }+781 \mathrm{C} / \mathrm{T}\end{array} \\
\end{array}$ & $\begin{array}{c}\text { Controls } \\
N=156(\%)\end{array}$ & $\begin{array}{c}\mathrm{CP} \\
N=278(\%)\end{array}$ & $P^{\mathrm{a}}$ & OR (95\% CI) & $\begin{array}{c}\mathrm{AgP} \\
N=58(\%)\end{array}$ & $P^{\mathrm{a}}$ & OR (95\% CI) \\
\hline TTC/TTC & $42(26.9)$ & $86(30.9)$ & NS & $1.18(0.74-1.87)$ & $17(29.3)$ & NS & $0.98(0.46-2.09)$ \\
\hline AGT/TTC & $63(40.4)$ & $101(36.3)$ & NS & $0.80(0.52-1.23)$ & $24(41.4)$ & NS & $1.13(0.57-2.24)$ \\
\hline ATT/TTC & $6(3.8)$ & $3(1.1)$ & 0.08 & $0.22(0.05-1.06)$ & $2(3.4)$ & NS & $1.03(0.19-5.49)$ \\
\hline TGC/TTC & $4(2.6)$ & $1(0.4)$ & 0.046 & $\begin{array}{c}0.09 \\
(0.01-0.96)\end{array}$ & $0(0.0)$ & NS & * \\
\hline AGC/TTC & $5(3.2)$ & $6(2.2)$ & NS & $0.90(0.24-3.36)$ & $1(1.7)$ & NS & $0.64(0.07-6.00)$ \\
\hline ATC/TTC & $0(0.0)$ & $6(2.2)$ & 0.08 & * & $1(1.7)$ & * & * \\
\hline TTT/TTC & $0(0.0)$ & $3(1.1)$ & NS & * & $0(0.0)$ & * & * \\
\hline TGT/TTC & $0(0.0)$ & $1(0.4)$ & * & $*$ & $0(0.0)$ & $*$ & $*$ \\
\hline AGT/AGT & $20(12.8)$ & $47(16.9)$ & NS & $1.60(0.87-2.93)$ & $10(17.2)$ & NS & $1.12(0.42-3.04)$ \\
\hline ATT/AGT & $1(0.6)$ & $5(1.8)$ & NS & $\begin{array}{c}2.12 \\
(0.20-22.08)\end{array}$ & $1(1.7)$ & * & $\begin{array}{c}3.36 \\
(0.20-55.97)\end{array}$ \\
\hline AGT/TGC & $4(2.6)$ & $3(1.1)$ & NS & $0.31(0.06-1.52)$ & $0(0.0)$ & NS & * \\
\hline AGT/AGC & $1(0.6)$ & $5(1.8)$ & NS & $\begin{array}{c}3.28 \\
(0.35-30.98)\end{array}$ & $1(1.7)$ & * & $\begin{array}{c}5.06 \\
(0.29-87.00)\end{array}$ \\
\hline AGT/ATC & $1(0.6)$ & $4(1.4)$ & NS & $2.52(0.27-23.83)$ & $0(0.0)$ & * & * \\
\hline ATT/ATT & $4(2.6)$ & $1(0.4)$ & 0.07 & $0.17(0.02-1.59)$ & $0(0.0)$ & NS & * \\
\hline TGC/TGC & $3(1.9)$ & $3(1.1)$ & NS & $0.71(0.13-3.82)$ & $1(1.7)$ & NS & $1.21(0.12-12.26)$ \\
\hline ATT/ATC & $1(0.6)$ & $0(0.0)$ & * & $*$ & $0(0.0)$ & * & $*$ \\
\hline ATC/ATC & $1(0.6)$ & $0(0.0)$ & * & $*$ & $0(0.0)$ & * & * \\
\hline TGT/TGT & $0(0.0)$ & $1(0.4)$ & $*$ & $*$ & $0(0.0)$ & $*$ & $*$ \\
\hline AGC/TGC & $0(0.0)$ & $1(0.4)$ & $*$ & $*$ & $0(0.0)$ & $*$ & $*$ \\
\hline \multicolumn{5}{|c|}{$P^{\mathrm{b}}=0.067$} & \multicolumn{3}{|c|}{$P^{\mathrm{b}}=\mathrm{NS}$} \\
\hline
\end{tabular}

OR: odds ratio adjusted for age, sex, and smoking in logistic regression; CI: confidence intervals.

${ }^{a}$ Differences between individual haplotypes (between controls and $\mathrm{CP}$ or controls and $\mathrm{AgP}$ ) were analyzed using the Fisher exact test.

${ }^{\mathrm{b}}$ Differences between individual haplotypes (between controls and CP or controls and AgP) were analyzed using the $\chi^{2}$ test.

${ }^{*}$ OR not calculated because of the presence of zero values.

Bold: significant result. 
(21.2\% versus $55.6 \%, P<0.05$; OR $=0.22,95 \% \mathrm{CI}=0.05-$ $0.91)$. In contrast, $I L 8-251 \mathrm{~T}$ allele carriers had an increased OR for individual presence of $A$. actinomycetemcomitans in $\operatorname{AgP}(N=21)$ patients $(91.7 \%$ versus $40.0 \%, P<0.01$; OR = $16.5,95 \% \mathrm{CI}=1.88-145.0)$ and also TT genotype was more often found in A. actinomycetemcomitans presence $(83.0 \%$ versus $13.3 \%, P<0.01$; OR $=32.5,95 \% \mathrm{CI}=2.38-443.2)$. Patients with CP $(N=151)$ carrying CC genotype of IL8 $+781 \mathrm{~T} / \mathrm{C}$ variant had less frequent presence of $T$. forsythia in their subgingival microflora than subjects without this genotype $(21.6 \%$ versus $35.1 \%, P<0.05$; OR $=0.51,95 \% \mathrm{CI}=$ $0.25-1.05)$. However, the relationship between periodontal bacteria and IL8 gene polymorphisms must be assessed very carefully regarding small numbers of subjects in the respective subgroups.

\section{Discussion}

Cytokines involved in the inflammatory process, such as IL8 and their genes, are important potential modifiers of individual susceptibility to AgP or CP. Although none of the investigated SNPs in the IL8 gene was individually associated with aggressive or chronic periodontitis, the patients with $\mathrm{CP}$ showed lower $\mathrm{A}(-251) / \mathrm{T}(+396) / \mathrm{T}(+781)$ and $\mathrm{T}(-251) / \mathrm{G}(+396) / \mathrm{C}(+781)$ haplotype frequencies than the controls. The association of TGC haplotype with CP was confirmed by the relationship between TGC/TTC haplotype (arranged as genotypes) and CP. These results confirm the hypothesis that haplotypes are more powerful for detecting susceptibility alleles than individual polymorphisms. Our results differ from those obtained by Scarel-Caminaga et al. [29] who associated ATC/TTC and AGT/TGC haplotypes with chronic periodontitis in the Brazilian population. These contradictory findings may be due to variability of the examined populations. For example, the frequency of the ATC haplotype in the Czech population was less than 3.4\%, compared to $23.7 \%$ in the Brazilians [29]. In the Brazilian population, some haplotypes of IL8 -845(T/C)/-738(T/A)/-353(A/T) variants showed significant association to, or protection against, CP [28]. Of the three IL8 SNPs, only one polymorphism was the same as in our study (i.e., SNP -251 (rs4073) referred to as -353 in Brazilian study). Polymorphism -845T/C (rs2227532) was also investigated in this study, but regarding a very low frequency of $\mathrm{C}$ allele, it was analyzed only in several individuals and therefore it was not included for any further haplotype assessment.

To date, eight studies evaluating the association of IL8 SNPs $(-251,+396$, and +781) and CP or AgP in different populations (mostly in Brazilian but none in the Caucasian population) have been performed, with contradictory results [27-32, 34, 35]. Most of these studies analyzed only the individual SNP and were focused on examining of CP; only Andia et al. [32] studied the relationship between IL8-251 variant and AgP; however, no association was found. Similarly, Kim et al. [27] failed to find any association between CP and allele or genotype distribution of IL8-251 SNP. In contrast, another study discovered a significant association between IL8 -251 SNP and CP in nonsmokers. The IL8 -251TA heterozygote genotype was associated with increased levels of IL8 mRNA transcripts and A allele had an increased risk for developing periodontitis [30]. This is consistent with the observation that the A allele of SNP IL8 -251 tended to be associated with higher IL-8 production in lipopolysaccharide- (LPS-) stimulated human whole blood [25]. Very recently, Li et al. [34] found that A allele of IL8 -251 variant was associated with decreased susceptibility to CP in Chinese population. Houshmand et al. [35] found a significant difference in the genotype frequencies of IL8 -251A/T and +396G/T SNPs between subjects with periodontitis and a control group in Hamedan, Iran, but did not specify whether it was for patients with CP or AgP. Conversely, Corbi et al. [31] showed that the genetic susceptibility to CP in the IL 8 gene was not associated with worse periodontal clinical parameters and increased IL-8 concentration. With the exception of Scarel-Caminaga et al. [29] who associated the +396TT genotype with CP, no association between SNP at position +396 or +781 and CP in the Brazilian population was discovered.

Several studies have examined polymorphisms in interleukins in connection with a subgingival bacterial colonization in patients with periodontitis. In this study, SNPs in the gene encoding IL- 8 were associated with the presence of pathogenic bacteria in subgingival dental plaque. The results showed that IL8 -251T allele carriers had an increased OR for the individual presence of $A$. actinomycetemcomitans in AgP patients $(P<0.01)$ and an increased OR was also found for the presence of T. forsythia for T allele of IL8 +781 in $\mathrm{CP}$ patients $(P<0.05)$. These data are in agreement with the notion that individual genetic susceptibility may influence the host response to infection [39]. Nibali et al. [40] found association between IL6 SNPs and A. actinomycetemcomitans, which they confirmed by the haplotype analysis. Specifically, IL6 -174GG genotype was associated with high (above median) counts of $A$. actinomycetemcomitans (both in all subjects and periodontally healthy subjects only) in Indians [41]. But Nibali et al. [42] also suggested that only a detection of known periodontopathogenic bacteria could not discriminate different forms of periodontitis. In contrast, Schulz et al. [43] found no evidence that SNPs in IL1 gene cluster could be associated with subgingival colonization with A. actinomycetemcomitans and could thus be an independent risk indicator of AgP. In addition, Finoti et al. [44] observed that periodontal destruction may occur in patients who are considered to be genetically susceptible to $\mathrm{CP}$ with a lower microbial challenge because of the presence of the IL 8 ATC/TTC haplotype than in patients without this haplotype.

There are some limitations to this study that need to be considered. First, the major complicating factor in the study of isolated locus (such as IL8) is the nature of periodontitis as a multifactorial disease in which interaction between multiple genes plays a role and each genetic polymorphism has generally only a small effect. In addition, the interaction of gene variants with environmental factors (such as bacterial pathogens), socioeconomic factors, BMI, and others not analyzed in this study, potentially affect the observed phenotype. Second, the case-control approach used is generally quite vulnerable to the population stratification, for example, due to different ethnic origin. The present sample, however, 
is exclusively of the Czech Caucasian origin, restricted to the limited geographical area populated by quite homogeneous population with low admixture. Finally, we did not measure RNA expression or protein levels of IL-8, therefore, we do not know the functional consequences of these polymorphisms in our subjects.

In conclusion, although none of the investigated SNPs in the IL8 gene were individually associated with periodontitis, some haplotypes can be protective against $\mathrm{CP}$ in the Czech population. Clinical significance of these findings is low due to a very low frequency of the "protective" haplotypes. The individual IL8 variants were associated with subgingival colonization with $A$. actinomycetemcomitans in AgP and with T. forsythia in CP in the Czech population. However, these relationships must be assessed very carefully regarding small numbers of subjects in the respective subgroups. Further studies are needed to clarify the association of these polymorphisms with periodontal diseases in other populations.

\section{Conflict of Interests}

The authors declare that they have no conflict of interests associated with this work.

\section{Acknowledgments}

This study was supported by the Internal Grant Agency (IGA NT11405-6) of the Czech Republic Ministry of Health and by project MUNI/A/0888/2012.

\section{References}

[1] S. S. Socransky, A. D. Haffajee, M. A. Cugini, C. Smith, and R. L. Kent Jr., "Microbial complexes in subgingival plaque," Journal of Clinical Periodontology, vol. 25, no. 2, pp. 134-144, 1998.

[2] G. C. Armitage, "Clinical evaluation of periodontal diseases," Periodontology 2000, vol. 7, pp. 39-53, 1995.

[3] R. Genco, K. S. Kornman, R. Williams et al., "Consensus report periodontal diseases: pathogenesis and microbial factors," Annals of Periodontology, vol. 1, pp. 926-932, 1996.

[4] G. C. Armitage, "Comparison of the microbiological features of chronic and aggressive periodontitis," Periodontology 2000, vol. 53, no. 1, pp. 70-88, 2010.

[5] B. Riep, L. Edesi-Neuß, F. Claessen et al., "Are putative periodontal pathogens reliable diagnostic markers?" Journal of Clinical Microbiology, vol. 47, no. 6, pp. 1705-1711, 2009.

[6] A. Mombelli, F. Casagni, and P. N. Madianos, "Can presence or absence of periodontal pathogens distinguish between subjects with chronic and aggressive periodontitis? A systematic review," Journal of Clinical Periodontology, vol. 29, no. 3, pp. 10-21, 2002.

[7] B. S. Michalowicz, D. Aeppli, J. G. Virag et al., "Periodontal findings in adult twins," Journal of Periodontology, vol. 62, no. 5, pp. 293-299, 1991.

[8] B. S. Michalowicz, "Genetic and heritable risk factors in periodontal disease," Journal of Periodontology, vol. 65, no. 5, pp. 479-488, 1994.

[9] R. C. Page and K. S. Kornman, "The pathogenesis of human periodontitis: an introduction," Periodontology 2000, vol. 14, pp. 9-11, 1997.
[10] K. Matsushima and J. J. Oppenheim, "Interleukin 8 and MCAF: novel inflammatory cytokines inducible by IL 1 and TNF," Cytokine, vol. 1, no. 1, pp. 2-13, 1989.

[11] C. Gronhoj Larsen, A. O. Anderson, E. Appella, J. J. Oppenheim, and K. Matsushima, "The neutrophil-activating protein (NAP1) is also chemotactic for T lymphocytes," Science, vol. 243, no. 4897, pp. 1464-1466, 1989.

[12] G. Godaly, L. Hang, B. Frendeus, and C. Svanborg, “Transepithelial neutrophil migration is CXCR1 dependent in vitro and is defective in IL-8 receptor knockout mice," Journal of Immunology, vol. 165, no. 9, pp. 5287-5294, 2000.

[13] G. T.-J. Huang, S. K. Haake, and N.-H. Park, "Gingival epithelial cells increase interleukin-8 secretion in response to Actinobacillus actinomycetemcomitans challenge," Journal of Periodontology, vol. 69, no. 10, pp. 1105-1110, 1998.

[14] A. Sfakianakis, C. E. Barr, and D. Kreutzer, "Mechanisms of Actinobacillus actinomycetemcomitans-induced expression of interleukin-8 in gingival epithelial cells," Journal of Periodontology, vol. 72, no. 10, pp. 1413-1419, 2001.

[15] Y. Kusumoto, H. Hirano, K. Saitoh et al., "Human gingival epithelial cells produce chemotactic factors interleukin-8 and monocyte chemoattractant protein-1 after stimulation with Porphyromonas gingivalis via Toll-like receptor 2," Journal of Periodontology, vol. 75, no. 3, pp. 370-379, 2004.

[16] K. H. Shinsuke Onishi, S. Liang, P. Stathopoulou, D. Kinane, G. Hajishengallis, and A. Sharma, "Toll-like receptor 2-mediated interleukin-8 expression in gingival epithelial cells by the Tannerella forsythia leucine-rich repeat protein BspA," Infection and Immunity, vol. 76, no. 1, pp. 198-205, 2008.

[17] M. Tamura, M. Tokuda, S. Nagaoka, and H. Takada, "Lipopolysaccharides of Bacteroides intermedius (Prevotella intermedia) and Bacteroides (Porphyromonas) gingivalis induce interleukin-8 gene expression in human gingival fibroblast cultures," Infection and Immunity, vol. 60, no. 11, pp. 4932-4937, 1992.

[18] C. C. Tsai, Y. P. Ho, and C. C. Chen, "Levels of interleukin-1 beta and interleukin- 8 in gingival crevicular fluids in adult periodontitis," Journal of periodontology, vol. 66, no. 10, pp. 852859, 1995.

[19] A. I. Dongari-Bagtzoglou and J. L. Ebersole, "Increased presence of interleukin-6 (IL-6) and IL-8 secreting fibroblast subpopulations in adult periodontitis," Journal of Periodontology, vol. 69, no. 8, pp. 899-910, 1998.

[20] C. Giannopoulou, J. J. Kamma, and A. Mombelli, "Effect of inflammation, smoking and stress on gingival crevicular fluid cytokine level," Journal of Clinical Periodontology, vol. 30, no. 2, pp. 145-153, 2003.

[21] P. Goutoudi, E. Diza, and M. Arvanitidou, "Effect of periodontal therapy on crevicular fluid interleukin-6 and interleukin-8 levels in chronic periodontitis," International Journal of Dentistry, vol. 2012, Article ID 362905, 8 pages, 2012.

[22] N. Mukaida, M. Shiroo, and K. Matsushima, "Genomic structure of the human monocyte-derived neutrophil chemotactic factor IL-8," Journal of Immunology, vol. 143, no. 4, pp. 13661371, 1989.

[23] M. F. Fey and A. Tobler, "An interleukin-8 (IL-8) cDNA clone identifies a frequent HindIII polymorphism," Human Genetics, vol. 91, no. 3, p. 298, 1993.

[24] E. Renzoni, P. Lympany, P. Sestini et al., "Distribution of novel polymorphisms of the interleukin- 8 and CXC receptor 1 and 2 genes in systemic sclerosis and cryptogenic fibrosing alveolitis," Arthritis and Rheumatism, vol. 43, no. 7, pp. 1633-1640, 2000. 
[25] J. Hull, A. Thomson, and D. Kwiatkowski, "Association of respiratory syncytial virus bronchiolitis with the interleukin 8 gene region in UK families," Thorax, vol. 55, no. 12, pp. 10231027, 2000.

[26] B. H. Rovin, L. Lu, and X. Zhang, "A novel interleukin-8 polymorphism is associated with severe systemic lupus erythematosus nephritis," Kidney International, vol. 62, no. 1, pp. 261265, 2002.

[27] Y. J. Kim, A. C. Viana, K. M. C. Curtis, S. R. P. Orrico, J. A. Cirelli, and R. M. Scarel-Caminaga, "Lack of association of a functional polymorphism in the interleukin 8 gene with susceptibility to periodontitis," DNA and Cell Biology, vol. 28, no. 4, pp. 185-190, 2009.

[28] Y. J. Kim, A. C. Viana, K. M. C. Curtis et al., "Association of haplotypes in the IL8 gene with susceptibility to chronic periodontitis in a Brazilian population," Clinica Chimica Acta, vol. 411, no. 17-18, pp. 1264-1268, 2010.

[29] R. M. Scarel-Caminaga, Y. J. Kim, A. C. Viana et al., "Haplotypes in the Interleukin 8 gene and their association with chronic periodontitis susceptibility," Biochemical Genetics, vol. 49, no. 56, pp. 292-302, 2011.

[30] D. C. Andia, N. F. P. De Oliveira, A. M. Letra, F. H. Nociti Jr., S. R. P. Line, and A. P. De Souza, "Interleukin-8 gene promoter polymorphism (rs4073) may contribute to chronic periodontitis," Journal of Periodontology, vol. 82, no. 6, pp. 893899, 2011.

[31] S. C. T. Corbi, G. Anovazzi, L. S. Finoti et al., "Haplotypes of susceptibility to chronic periodontitis in the Interleukin 8 gene do not influence protein level in the gingival crevicular fluid," Archives of Oral Biology, vol. 57, no. 10, pp. 1355-1361, 2012.

[32] D. C. Andia, A. Letra, R. C. Casarin, M. Z. Casati, S. R. Line, and A. P. de Souza, "Genetic analysis of the IL8 gene polymorphism (rs4073) in generalized aggressive periodontitis," Archives of Oral Biology, vol. 58, no. 2, pp. 211-217, 2013.

[33] M. P. Amaya, L. Criado, B. Blanco et al., "Polymorphisms of proinflammatory cytokine genes and the risk for acute suppurative or chronic nonsuppurative apical periodontitis in a Colombian population," International Endodontic Journal, vol. 46, no. 1, pp. 71-78, 2013.

[34] G. Li, Y. Yue, Y. Tian et al., "Association of matrix metalloproteinase (MMP)-1, 3, 9, interleukin (IL)-2, 8 and cyclooxygenase (COX)-2 gene polymorphisms with chronic periodontitis in a Chinese population," Cytokine, vol. 60, no. 2, pp. 552-560, 2012.

[35] B. Houshmand, M. Hajilooi, A. Rafiei, M. Bidgoli, and S. Soheilifar, "Evaluation of IL-8 gene polymorphisms in patients with periodontitis in Hamedan, Iran," Dental Research Journal, vol. 9, no. 4, pp. 427-432, 2012.

[36] G. C. Armitage, "Development of a classification system for periodontal diseases and conditions," Annals of Periodontology, vol. 4, no. 1, pp. 1-6, 1999.

[37] World Health Organisation, Oral Health Surveys: Basic Methods, WHO, Geneva, Switzerland, 4th ed edition, 1997.

[38] J. J. Sambrook, E. F. Fritsch, and T. Maniatis, Molecular Cloning: a Laboratory Manual, Cold Spring Harbor Laboratory Press, Cold Spring Harbor, NY, USA, 1989.

[39] G. S. Cooke and A. V. S. Hill, "Genetics of susceptibility to human infectious disease," Nature Reviews Genetics, vol. 2, no. 12, pp. 967-977, 2001.

[40] L. Nibali, M. S. Tonetti, D. Ready et al., "Interleukin-6 polymorphisms are associated with pathogenic bacteria in subjects with periodontitis," Journal of Periodontology, vol. 79, no. 4, pp. 677683, 2008.
[41] L. Nibali, I. Madden, F. Franch Chillida, L. J. A. Heitz-Mayfield, P. M. Brett, and N. Donos, "IL6 -174 Genotype Associated with Aggregatibacter actinomycetemcomitans in Indians," Oral Diseases, vol. 17, no. 2, pp. 232-237, 2011.

[42] L. Nibali, F. D’Aiuto, D. Ready, M. Parkar, R. Yahaya, and D. Donos, "No association between A. actinomycetemcomitans or P. gingivalis and chronic or aggressive periodontitis diagnosis," Quintessence International, vol. 43, no. 3, pp. 247-254, 2012.

[43] S. Schulz, J. M. Stein, W. Altermann et al., "Single nucleotide polymorphisms in interleukin-lgene cluster and subgingival colonization with Aggregatibacter actinomycetemcomitans in patients with aggressive periodontitis," Human Immunology, vol. 72, no. 10, pp. 940-946, 2011.

[44] L. S. Finoti, S. C. Corbi, G. Anovazzi et al., "Association between IL8 haplotypes and pathogen levels in chronic periodontitis," European Journal of Clinical Microbiology and Infectious Diseases, vol. 32, no. 10, pp. 1333-1340, 2013. 


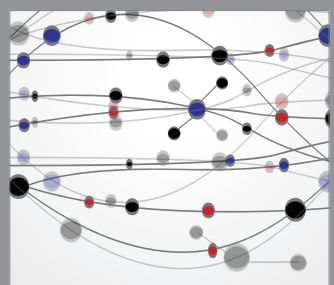

The Scientific World Journal
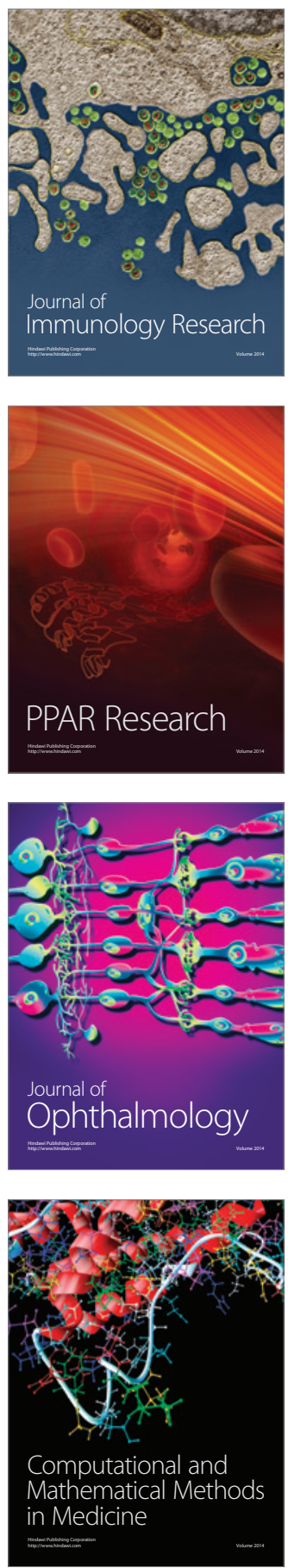

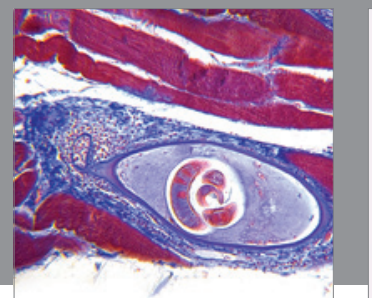

Gastroenterology

Research and Practice
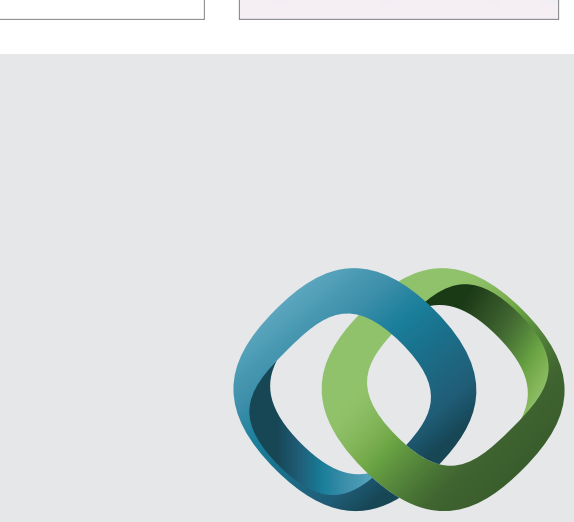

\section{Hindawi}

Submit your manuscripts at

http://www.hindawi.com
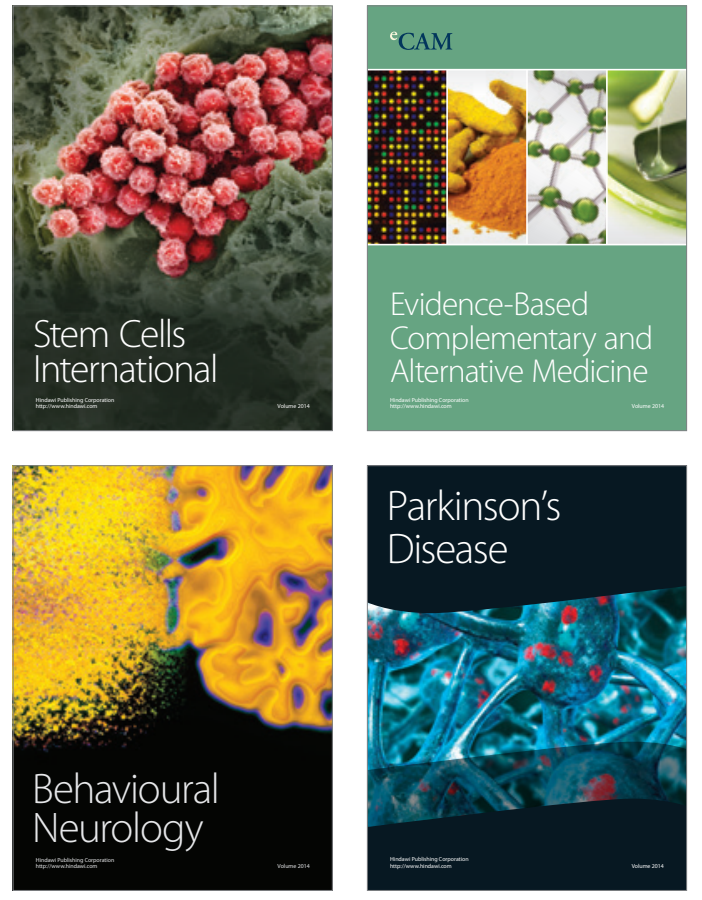
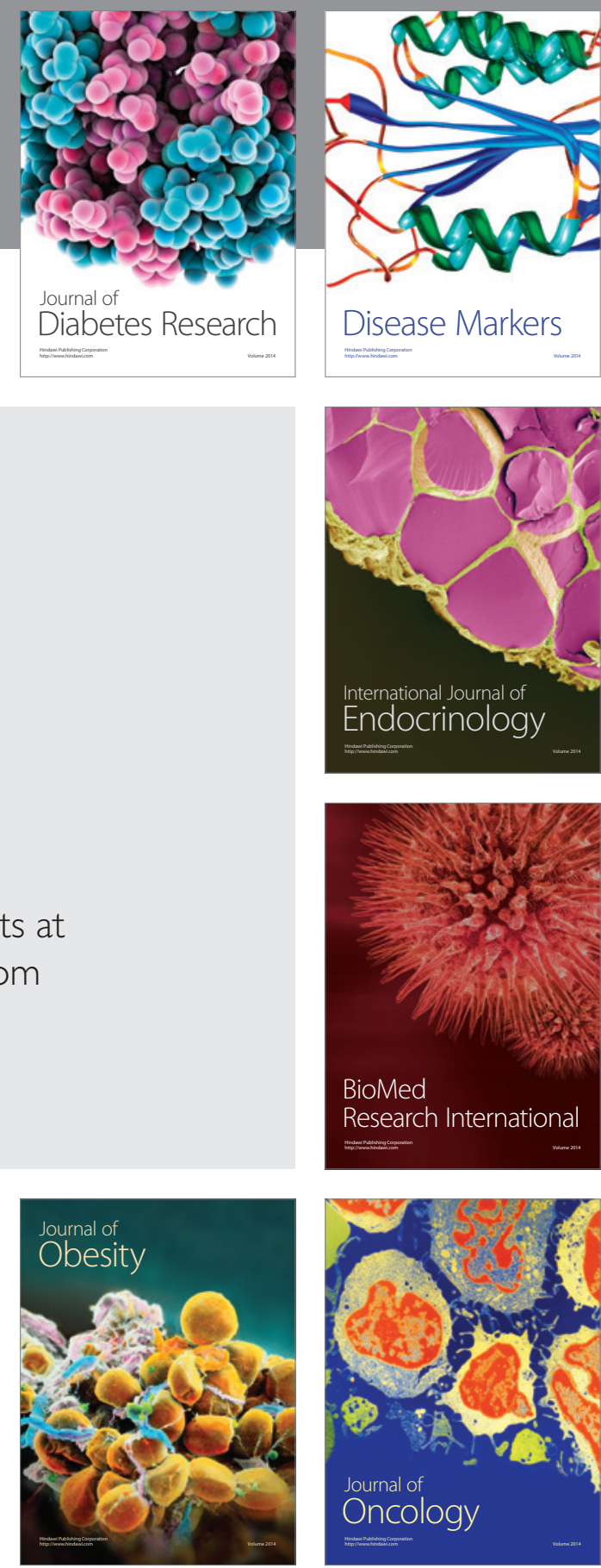

Disease Markers
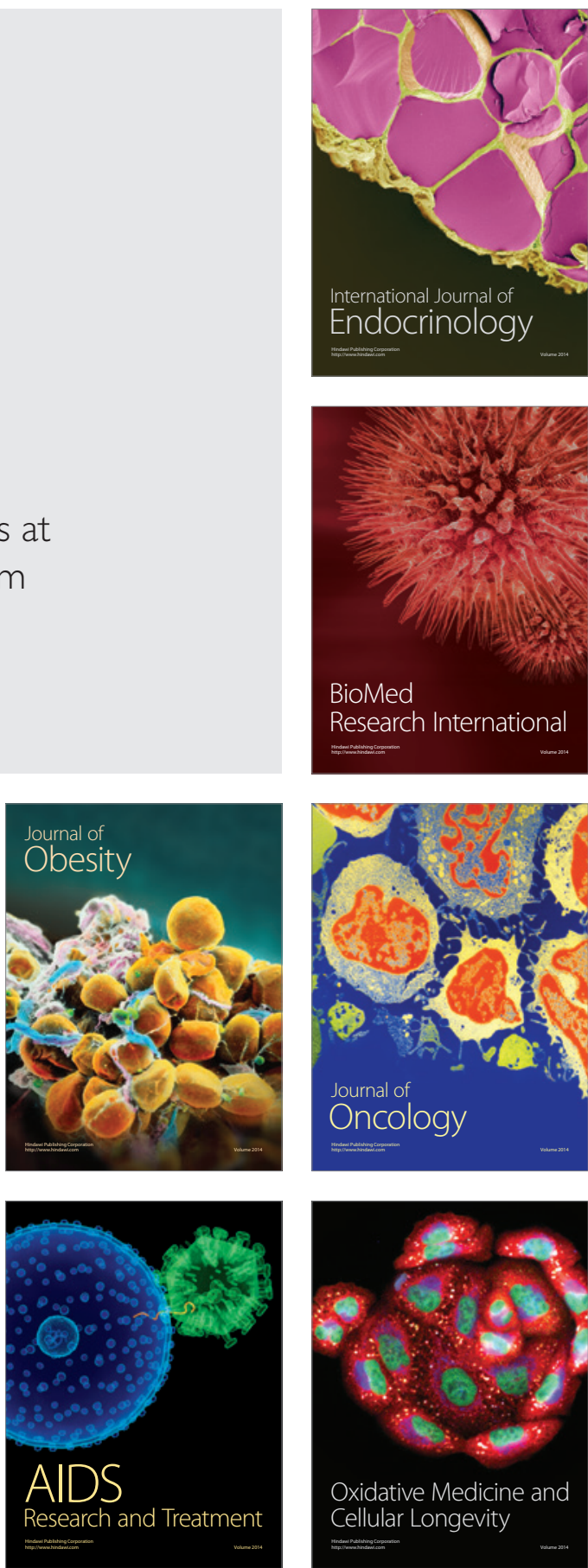